\title{
Augmentation of the acute phase response in vitamin C- supplemented ultramarathoners
}

\author{
E M Peters (PhD) 1 \\ R Anderson (PhD) ${ }^{2}$ \\ D C Nieman (PhD) ${ }^{3}$ \\ 'Department of Physiology, Nelson R Mandela School of Medicine, University of Kwa-Zulu-Natal, Durban \\ ${ }^{2}$ Medical Research Council Unit for Inflammation and Immunity, Department of Immunology, University of Pretoria \\ ${ }^{3}$ Department of Health and Exercise Sciences, Appalachian State University, Boone, USA
}

\begin{abstract}
Objective. To investigate the effects of vitamin C (VC) supplementation on the alterations in systemic markers of inflammation as a result of participation in a $90 \mathrm{~km}$ down run from Pietermaritzburg to Durban in 29 subjects who completed the 1999 Comrades Marathon.

Interventions. Runners were divided into groups receiving $500 \mathrm{mg} /$ day VC (VC500; $N=10), 1500 \mathrm{mg} /$ day VC (VC1500; $N=12$ ) or placebo $(\mathrm{P}, N=7)$ for 7 days before the race, on the day of the race, and for 2 days following completion.

Main outcome measures. Each subject recorded dietary intake before, during and after the race and provided 35 $\mathrm{ml}$ blood samples 15 - 18 hours before the race, immediately post race, 24 hours post race and 48 hours post race. These were analysed for full blood count, vitamins $A, C$ and $E$, glucose, C-reactive protein (CRP), amyloid $A$, interleukin-6 (IL-6) and interleukin-8 (IL-8) concentrations. All post race concentrations were adjusted for plasma volume changes.

Results. Analyses of dietary intakes and blood glucose and anti-oxidant status on the day preceding the race and the day of the race excluded carbohydrate intake or plasma vitamins $E$ and $A$ as significant confounders in the study. Mean pre-race concentrations of serum vitamin C in VC500 and VC1500 groups (128-10.2 and $153-10.2$ $\mathrm{mol} / \mathrm{l})$ were significantly higher $(p<0.01)$ than in the $\mathrm{P}$ group $(83-10.8 \mathrm{~mol} / \mathrm{l})$ and confirmed the additional dietary VC intake of both groups. Serum CRP concentrations were significantly higher $(p<0.05)$ in the VC500
\end{abstract}

\section{CORRESPONDENCE:}

\section{E M Peters}

Department of Physiology

Nelson R Mandela School of Medicine

Private Bag 7

Congella

4013

Tel: 031-260 4237

Fax: 031-260 4455

E-mail: futree@nu.ac.za group than in the VC1500 and P groups. This finding was supported by similar trends in serum amyloid $A$, plasma IL-6 and IL-8. When the data from the two VC groups were pooled and the vitamin intake in the placebo $(N=7)$ and VC $(N=22)$ groups compared, CRP concentrations in the VC groups were significantly higher at each of the post-race time points $(p<0.05)$.

Conclusion. These data confirm previous findings of a trend towards an enhanced pro-inflammatory response following $V C$ intake $\geq 500 \mathrm{mg}$ per day.

\section{Introduction}

It is well established that prolonged exercise results in delayed-onset muscle soreness (DOMS) which peaks after 24 - 48 hours and subsides after 5 - 7 days. ${ }^{8}$ This has been attributed to actual tissue damage which occurs during repetitive contraction of muscle fibres. The damage has been shown to be further exacerbated when the eccentric component of contraction is increased, as occurs during downhill long-distance running when muscles are used in a braking motion. . $^{17,18,20}$

The Comrades Marathon, a gruelling $90 \mathrm{~km}$ downhill foot race from Pietermaritzburg to Durban, South Africa, causes an intense, systemic, exercise-induced inflammatory response. As the evidence regarding the effect of vitamin C (VC) supplementation on systemic markers of inflammation following eccentric exercise is presently conflicting showing either no effect, ${ }^{10,11,14}$ an attenuation ${ }^{2,19}$ or evidence of an increased proinflammatory response, ${ }^{5,15}$ it was the purpose of this study to reinvestigate and extend on our previous study ${ }^{15}$ on the effect of oral VC supplementation on markers of the acute phase response and muscle damage following ultramarathon running in a more extensive work. We therefore undertook to examine the effects of supplementation using higher and lower dosages of VC in the same event 2 years later.

\section{Methods}

\section{Study design}

Approval to conduct the study was obtained from the Human Ethics Committee of the Nelson Mandela Medical School of the University of KwaZulu-Natal. Forty-five registered 
entrants for the 1999 Comrades Marathon signed informed consent forms and agreed to participate in the study. They were divided into 3 groups matched for age, gender, training status and expected race finishing time: (i) group 1 (placebo (P)) - placebo supplement (3 placebo tablets per day); (ii) group 2 (VC500) - one $500 \mathrm{mg} \mathrm{VC}$ tablet and 2 placebo tablets per day; (iii) group 3 (VC1500) - three 500 mg VC tablets per day.

Each subject was required to take 3 tablets per day over a 10-day period; 1 tablet with breakfast, lunch and supper on the 7 days preceding the race, the day of the race and 2 days following the race.

The study was double-blinded and based on a 3 ( 3 groups) by 4 ( 4 blood samples) repeated measures design.

On the day prior to the race, subjects were required to complete 24-hour dietary records of their intake both in terms of food and supplements, and to report for basic anthropometric measurements and blood sampling on the afternoon prior to the race at a time that coincided with their estimated finishing time (in order to avoid the effect of diurnal rhythms on hormone concentrations). Within 30 - 45 minutes of completing the race, the subjects again gave $35 \mathrm{ml}$ blood samples and were asked to detail their dietary and liquid intakes on the morning of the race and during the race. The blood sampling was repeated 24 hours and 48 hours after the race and subjects were asked to record their post-race dietary intakes for a further 36 hours after the race.

\section{Dietary analyses}

Intake of both food and nutritional supplements were analysed using the Dietary Manager computer program (Program Management, Randburg, South Africa). Total daily carbohydrate $(\mathrm{CHO})$ and $\mathrm{VC}$ intakes during the 24 hours before the race, on the day of the race, and after the race, including intake derived from any additional $\mathrm{CHO}$ supplements used by the athletes, were determined.

\section{Treatment of blood}

Venous blood samples collected in glass Vacutainer tubes containing ethylenediaminetetraacetic acid ( $\left.\mathrm{K}_{3}-\mathrm{EDTA}\right)$ were used for determination of full blood counts. A $15 \mathrm{ml}$ aliquot was allowed to clot at room temperature and centrifuged for 10 minutes; aliquots of serum were quick-frozen and stored at $-70 \ldots$ for later analysis of VC, C-reactive protein (CRP) and amyloid $A$. The remainder was drawn into vacutainer tubes containing $\mathrm{K}_{3}$-EDTA and the plasma stored at -70 ...C for later analysis of vitamins $E$ and $A$, glucose, and interleukin (IL)-6 and IL-8 concentrations.

\section{Haematological analyses and adjustments}

Full blood counts were performed on $\mathrm{K}_{3}$-EDTA- treated specimens using standard haematological procedures on an automated model (Coulter Electronics Inc., Hialeah, Florida, USA). Plasma volume changes were determined from preand post-race haemoglobin and haematocrit values using the method of Dill and Costill ${ }^{6}$ and all subsequent post-race concentrations (at 0,24 and 48 hours) were adjusted for these plasma volume changes.

\section{Serum acute phase reactants, vitamins C, A and E}

Serum concentrations of the acute phase reactants, CRP (normal range $0-5 \mathrm{~g} / \mathrm{ml}$ ) and amyloid A (normal range 6 $8 \mathrm{~g} / \mathrm{ml}$ ), were measured using a nephelometric procedure (Behring Nephelometer II) with reagents purchased from Behringwerke AG, Marburg, Germany. VC was extracted from the serum using $20 \%$ trichloracetic acid and assayed using the 2,4-dinitrophenylhydrazine colorimetric method (Sigma Chemical Co., St Louis, MO, USA), while plasma concentrations of vitamins $A$ and $E$ were determined using standard high-performance liquid chromatography (HPLC) procedures following repeated $(x 3)$ extraction with hexane and using vitamin $\mathrm{A}$-acetate as the internal standard. ${ }^{4}$

\section{Plasma glucose, IL-6 and IL-8}

Plasma glucose concentrations were determined spectrophotometrically in pre-race, immediate, 24-hour and 48hour post-race samples. The plasma IL- 6 and IL- 8 analyses were part of a more comprehensive study on the cytokine profile of ultramarathon runners, ${ }^{11}$ but were adjusted for plasma volume changes in this report. These were assayed using quantitative sandwich enzyme-linked immunosorbent assay (ELISA) kits provided by R\&D Systems, Inc. (Minneapolis, MN, USA). A standard curve was constructed using standards provided in the kits. The assays were twostep sandwich enzyme immunoassay procedures in which samples or standards were incubated in 96-well microtiter plates coated with polyclonal antibodies for the test cytokine as the capture antibody. Following the appropriate incubation time, the wells were washed and a second detection antibody conjugated to horseradish peroxidase was added. The plates were incubated and washed, and the amount of bound enzyme-labelled detection antibody was measured by adding a chromogenic substrate. The plates were then read at the appropriate wavelength ( 450 minus $570 \mathrm{~nm}$ ). The minimum detectable concentration of IL- 6 was $<0.094 \mathrm{pg} / \mathrm{ml}$, and of IL-8 $<10 \mathrm{pg} / \mathrm{ml}$.

\section{Statistical analyses}

Data are reported as mean (- standard error of the mean (SEM)). Due to the small sizes of the groups and the large variability of the test result values within the groups, conservative non-parametric statistics were used. A Kruskal-Wallis test was used to compare the mean ranks of the 3 groups at each of the time points. If this revealed significance, a twotailed Wilcoxon s two-sample test was used to establish whether the difference between the placebo group and the VC500 or VC1500 groups was significant $(p<0.05)$.

The data in the VC500 and VC1500 groups were subsequently pooled and an independent, two-sample MannWhitney test was used to establish whether the placebo group $(N=7)$ differed significantly from the VC group $(N=22)$, irre- 
spective of the dosage differences, at each time point. Box and whisker plots were used to illustrate the variability around the medians of the 2 groups. A repeated measures analysis of variance (ANOVA) procedure was used on the logged data to perform a profile analysis of each of the measured outcomes. These data were graphically represented using profile plots showing the estimated marginal means of the 2 groups as a function of time.

Spearman s correlation coefficient was used as a measure of association. Statistical analysis was executed using SPSS Inc (Chicago, Illinois) statistical software.

\section{Results}

\section{Subject characteristics}

Of the initial 45 athletes registered to participate, only 29 completely fulfilled the protocol requirements of the study. The characteristics of the subjects are given in Table I. There were no significant differences between the three groups with regard to age, height, mass, body mass index, training status, and time taken to complete the ultramarathon.

\section{CHO intake, plasma glucose and vitamins $A$ and $E$}

Mean (- SEM) dietary $\mathrm{CHO}$ intakes and plasma concentrations of glucose on the day preceding the race and on the day of the race are presented in Table II. CHO intake just prior to and during the race averaged $401(-39) \mathrm{g}$ and did not differ

\section{TABLE I. Subject characteristics $(N=29)$}

\begin{tabular}{lll}
\hline Characteristic & Mean ( \pm SEM) & Range \\
\hline Age $(\mathrm{yrs})$ & $39.7(-1.3)$ & $27-54$ \\
Body mass $(\mathrm{kg})$ & $70.4(-2.0)$ & $53.2-97.0$ \\
Stature $(\mathrm{m})$ & $1.74(-0.02)$ & $1.57-1.89$ \\
Body mass index $(\mathrm{kg} / \mathrm{m} 2)$ & $23.2(-0.5)$ & $18.7-28.7$ \\
Race time $(\mathrm{hrs})$ & $9.73(-0.18)$ & $7.38-11.08$ \\
Weekly training distance $(\mathrm{km})$ & $87.9(-4.92)$ & $70-120$ \\
& &
\end{tabular}

TABLE II. Mean ( \pm SEM) dietary carbohydrate (CHO) intakes and plasma concentrations of glucose on the day preceding the race and the day of the race

\begin{tabular}{|lll}
\hline & & $\begin{array}{l}\text { Plasma } \\
\text { glucose } \\
\text { (mmol/l) }\end{array}$ \\
\hline Day preceding the race & & \\
Placebo $(N=7)$ & $399(-29.1)$ & $4.69(-0.3)$ \\
VC500 $(N=10)$ & $499(-51.3)$ & $4.95(-0.3)$ \\
VC1500 $(N=12)$ & $482(-42.2)$ & $4.74(-0.2)$ \\
Day of the race & & \\
Placebo $(N=7)$ & $315(-54.8)$ & $6.14(-0.6)$ \\
VC500 $(N=10)$ & $353(-35.2)$ & $6.47(-0.5)$ \\
VC1500 $(N=12)$ & $488(-65.7)$ & $5.95(-0.3)$ \\
& & \\
\hline
\end{tabular}

significantly between the groups. Likewise, pre- and postrace plasma glucose (Table II), vitamin $A$ and vitamin $E$ concentrations (not shown) were not different between the 3 groups $(p>0.05)$.

\section{Blood counts}

Selected results of the full blood counts are given in Table III. Packed cell volume and haemoglobin concentrations indicated a varied hydration status ranging from a mean per cent plasma volume drop of $1.7 \%$ in the VC500 group to $7.1 \%$ in the placebo group in the immediate post-race samples (Table II). Although $72.5 \%$ of the sample $(N=29)$ presented with a decrease in plasma volume immediately following completion of the ultramarathon, the greatest majority $(62.1 \%$ and $100 \%)$ presented with increases in plasma volume in the 24-hour and 48-hour post-race samples, respectively. The differences in plasma volume between the groups did not, however, reach statistical significance $(p>0.05)$.

Significant immediate post-race lymphopenia and neutrophilia were present in all 3 groups with recovery to normal values at 24 and 48 hours after completion of the race. The circulating neutrophil count was significantly lower in the VC1500 group $(N=12)$ in immediate post-race samples, while postrace lymphopenia was less pronounced in the VC1500 group, resulting in the immediate post-race neutrophil/lymphocyte ratio being lowest in this group $(p<0.05)$. Mean monocyte levels rose significantly in all 3 groups as a result of the prolonged exertion and remained elevated for the 48-hour post-race period with no significant differences between the 3 groups.

\section{Serum vitamin C}

The results of the serum VC concentrations in the three groups at the four time-points are shown in Fig. 1. Pre-race serum VC was significantly higher in the supplemented groups compared with the P group. The significant mean increase $(42.6 \mu \mathrm{mol} / \mathrm{l})$ in serum VC in the $\mathrm{P}$ group immediately post race was less in both of the vitamin-supplemented groups (19.3 and -2.84 $\mu \mathrm{mol} / \mathrm{l}$ in the VC500 and VC1500 groups, respectively). At 24 and 48 hours after completion of the race the serum VC concentrations returned to close to pre-race values.

\section{Circulating concentrations of plasma IL-6 and IL-8}

The mean immediate post-race concentrations of the

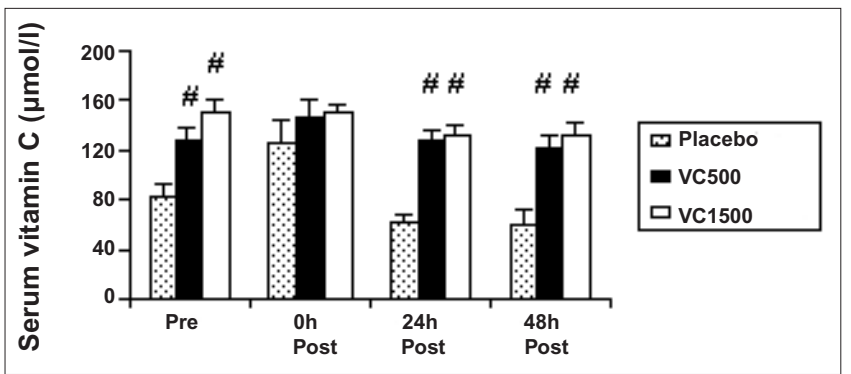

Fig. 1. Mean ( $\pm S E M)$ serum vitamin $C$ concentrations before and after participation in a $90 \mathrm{~km}$ ultramarathon (\# $p<0.01$, two-tailed Wilcoxon's test, $v$. placebo at this time point). 


\begin{tabular}{|c|c|c|c|c|}
\hline Variable & Pre-race & $\begin{array}{l}\text { Post-race } \\
\text { (0.5 - } 1 \text { hour) }\end{array}$ & $\begin{array}{l}\text { Post-race } \\
\text { (24 hours) }\end{array}$ & $\begin{array}{l}\text { Post-race } \\
\text { (48 hours) }\end{array}$ \\
\hline \multicolumn{5}{|c|}{$\%$ PV change * } \\
\hline Placebo & & $7.11(-2.98)$ & $-2.23(-3.55)$ & $9.45(-2.54)$ \\
\hline VC500 & & $1.73(-1.80)$ & $7.74(-2.26)$ & $12.3(-2.25)$ \\
\hline VC1500 & & $6,73(-2.24)$ & $5.43(-2.64)$ & $15.6(-2.23)$ \\
\hline \multicolumn{5}{|c|}{ Total leukocytes $\left(10^{9} / 1\right)$} \\
\hline Placebo & $7.62(-1.07)$ & $18.1(-2.5)$ & $8.66(-1.03)$ & $8.09(-1.04)$ \\
\hline VC500 & $7.96(-1.09)$ & $16.6(-1.2)$ & $9.37(-0.68)$ & $7.75(-0.31)$ \\
\hline VC1500 & $6.52(-0.48)$ & $14.2(-1.1)$ & $8.14(-0.66)$ & $7.24(-0.46)$ \\
\hline \multicolumn{5}{|c|}{ Neutrophils $\left(10^{9} / l\right)$} \\
\hline Placebo & $4.43(-0.91)$ & $15.2(-2.2)$ & $5.14(-0.13)$ & $4.04(-0.79)$ \\
\hline VC500 & $4.82(-1.08)$ & $13.8(-0.9)$ & $5.64(-0.57)$ & $3.59(-0.26)$ \\
\hline VC1500 & $3.45(-0.35)+$ & $11.0(-1.0)+$ & $4.43(-0.08)$ & $3.10(-1.10)$ \\
\hline \multicolumn{5}{|c|}{ Lymphocytes $\left(10^{9} / l\right)$} \\
\hline Placebo & $2.11(-0.12)$ & $1.6(-0.3)$ & $2.4(-0.3)$ & $2.3(-0.3)$ \\
\hline VC500 & $2.21(-0.12)$ & $1.3(-0.1)$ & $2.6(-0.2)$ & $2.2(-0.1)$ \\
\hline VC1500 & $2.25(-0.21)$ & $2.0(-0.3)+$ & $2.7(-0.2)$ & $2.4(-0.2)$ \\
\hline \multicolumn{5}{|c|}{ Neutro/lymph ratio } \\
\hline Placebo & $2.10(-0.37)$ & $11.9(-2.3)$ & $2.5(-1.5)$ & $2.2(-1.1)$ \\
\hline VC500 & $2.31(-0.62)$ & $10.7(-1.3)$ & $2.4(-0.9)$ & $1.7(-0.5)$ \\
\hline VC1500 & $1.53(-0.25)$ & $7.0(-1.9)+$ & $2.0(-1.5)$ & $1.5(-0.8)$ \\
\hline \multicolumn{5}{|c|}{ Monocytes $\left(10^{9} / l\right)$} \\
\hline Placebo & $0.46(-0.05)$ & $1.36(-0.15)$ & $0.76(-0.10)$ & $0.73(-0.10)$ \\
\hline VC500 & $0.61(-0.07)$ & $1.00(-0.25)$ & $1.00(-0.10)$ & $0.76(-0.06)$ \\
\hline VC1500 & $0.61(-0.05)$ & $1.05(-0.14)$ & $0.79(-0.07)$ & $0.79(-0.05)$ \\
\hline
\end{tabular}

chemotactic cytokine, IL-8, were more than 5-fold higher than mean pre-race concentrations and subsided to close to pre-race concentrations at 24 and 48 hours after completion of the race (Table IV). Plasma IL-8 concentrations correlated strongly $(r=0.67)$ with absolute neutrophil numbers in the circulation (Table III). The increase in the mean circulating concentrations of IL-8, observed immediately post-race, were greater in the $500 \mathrm{mg}$ group than in the $\mathrm{P}$ group, but the difference did not reach statistical significance $(p=0.14)$.

Circulating IL- 6 concentrations showed a similar trend to that of IL-8, with a greater than 20 -fold increase in concentrations following completion of the downhill ultramarathon, which subsided within 48 hours. However, throughout the 48-hour recovery the mean concentrations of IL-6 in the VC500 group remained elevated above those of the $\mathrm{P}$ group, but the difference did not reach statistical significance $(p=0.11)$.

\section{Serum CRP and amyloid A concentrations}

Both acute phase proteins measured in this study revealed a similar trend (Figs 2 and 3). When concentrations in the 3 groups were compared at the 24 and 48-hour post-race timepoint a Kruskal-Wallis test revealed a significant difference in the circulating CRP concentration $(p<0.05)$. Similar trends

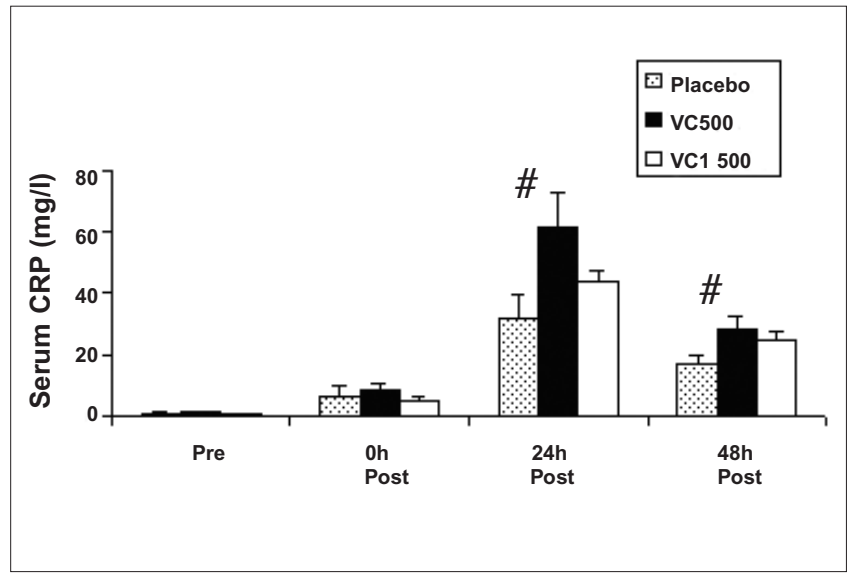

Fig. 2. Mean ( \pm SEM) serum CRP concentrations before and after participation in a $90 \mathrm{~km}$ ultramarathon \# $p<0.01$, twotailed Wilcoxon's test, v. placebo at this time point).

were observed for amyloid-A, but were not statistically significant due to large intra-group variance. A subsequent Wilcoxon s two-sample test revealed significant differences $(p=0.03 ; 0.04)$ between the VC500 and P groups for serum CRP at the 24 and 48-hour post-race time-points. However, the increments in mean CRP concentrations were not signif- 


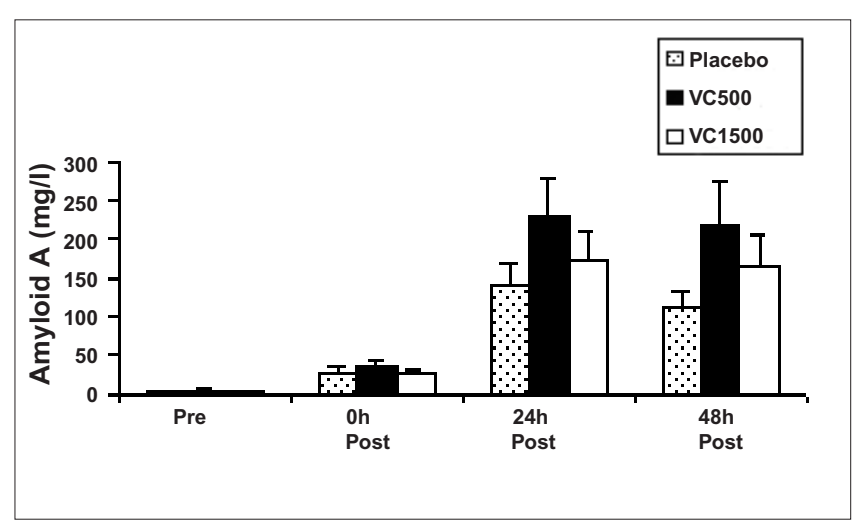

Fig. 3. Mean ( \pm SEM) serum amyloid A concentrations before and after participation in a $90 \mathrm{~km}$ ultramarathon.

icant at any of the post-race time points in the VC1500 group.

However when the data from the 2 VC groups were pooled $(N=22)$ and compared with the $\mathrm{P}$ group $(N=7)$, the MannWhitney test showed significant differences of serum CRP concentrations between the 2 groups at 0 hours ( $p=0.037$ ), 24 hours $(p=0.048)$ and 48 hours $(p=0.048)$ post race. In terms of amyloid A, IL-6 and IL-8, the difference between the 2 groups was not significant at any of the time-points $(p>0.05)$. A box and whisker plot illustrating the variability around the median is provided in Fig. 4 and indicates that the median of the $\mathrm{P}$ group did lie outside the interquartile range of the VC group at all 3 post-race time-points for serum CRP concentrations.

Repeated measures ANOVA showed no evidence of an interaction between the 2 groups over time for serum CRP con-

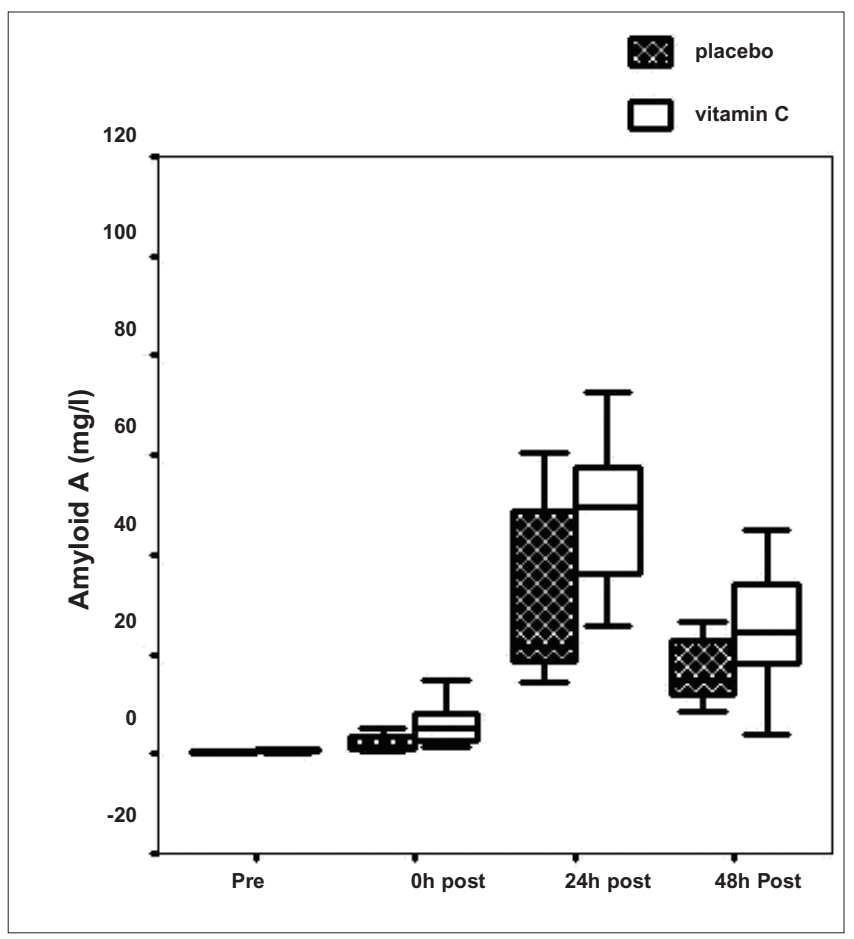

Fig. 4. A box and whisker representation of the variability of the serum CRP concentrations in placebo $(N=7)$ and pooled vitamin $C(N=22)$ groups at the four time points. centrations $(p=0.534)$. The effect of VC supplementation was significantly different from the $P$ group at all time-points ( $f=$ $6.664, p=0.016$ ). The profiles of amyloid A and IL-8 were identical, but co-incident $(p=0.458 ; 0.861)$. A profile plot of the logged serum CRP concentration data is presented in Fig. 5.

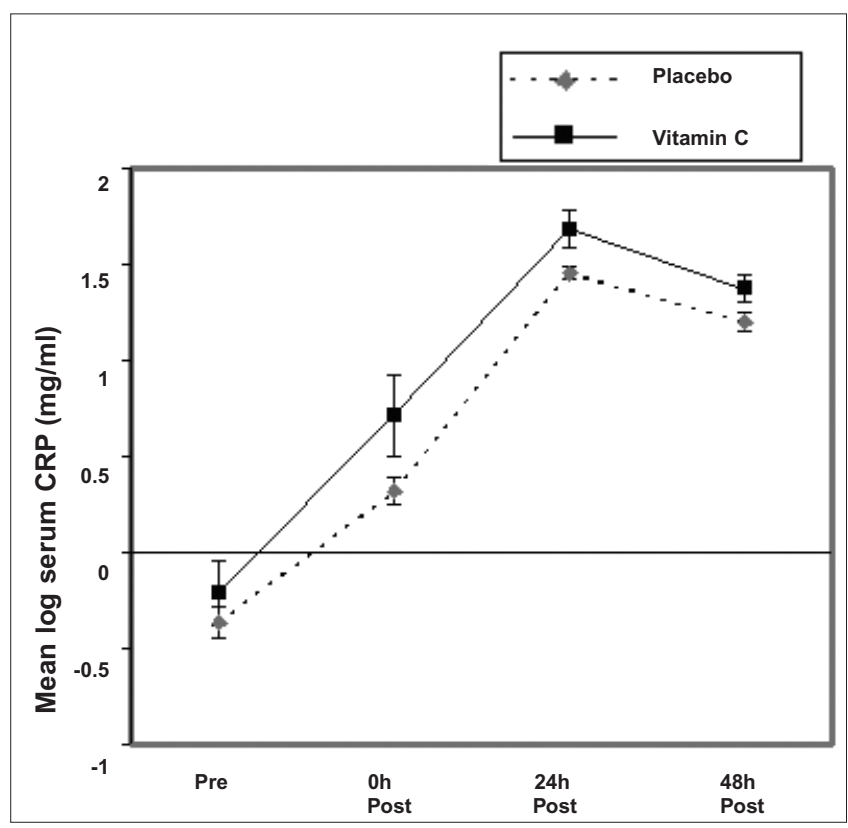

Fig. 5. Profile plot of the logged serum CRP concentrations of the placebo $(N=7)$ and pooled vitamin $C(N=22)$ groups at the four time points.

\section{Discussion}

The results of the serum VC concentrations within the 3 groups confirm significant elevations in the supplemented groups when compared with those in the $\mathrm{P}$ group. In contrast, insignificantly different plasma glucose concentrations in the 3 groups following the race confirm the absence of this factor as a possible extraneous variable influencing VC uptake and absorption in the 3 groups. ${ }^{9}$

\begin{tabular}{|c|c|c|c|c|}
\hline Variable & Pre-race & $\begin{array}{l}\text { Post-race } \\
\text { ( } 0.5-1 \text { hour) }\end{array}$ & $\begin{array}{l}\text { Post-race } \\
\text { (24 hours) }\end{array}$ & $\begin{array}{l}\text { Post-race } \\
48 \text { hours) }\end{array}$ \\
\hline \multicolumn{5}{|l|}{ IL-6 (pg/ml) } \\
\hline Placebo & $3.6(-2.4)$ & $92.5(-22.3)$ & $4.7(-2.4)$ & $4.2(-1.2)$ \\
\hline VC500 & $3.5(-1.8)$ & $112(-26.3)$ & $6.8(-1.8)$ & $4.5(-1.8)$ \\
\hline VC1500 & $2.5(-0.8)$ & $73.1(-6.2)$ & $6.5(-1.7)$ & $4.2(-1.8)$ \\
\hline \multicolumn{5}{|l|}{ IL-8 (pg/ml) } \\
\hline Placebo & $4.0(-0.5)$ & $22.1(-4.2)$ & $3.6(-0.6)$ & $3.4(-0.5)$ \\
\hline VC500 & $3.7(-0.7)$ & $28.0(-6.6)$ & $3.7(-0.7)$ & $3.2(-0.7)$ \\
\hline VC1500 & $4.2(-1.8)$ & $18.4(-2.0)$ & $5.6(-0.9)$ & $3.3(-0.4)$ \\
\hline
\end{tabular}


When the results of each of the markers of transient systemic inflammatory response syndrome (SIRS) measured in this study are considered collectively, participation in this $90 \mathrm{~km}$ downhill ultramarathon resulted in evidence of a substantial pro-inflammatory response which was confirmed by significant post-race elevations in neutrophil count, plasma IL-6, IL-8, serum CRP and serum amyloid concentration. This evidence of SIRS appeared to be exacerbated in the VC500 group when compared with the placebo and VC1500 groups.

The development of an inflammatory reaction is known to be controlled by cytokines. While IL- 6 is released from activated T-helper- 2 cells at the site of the damaged tissue, the chemokine, IL-8, is known to mediate inflammation via its ability to attract and activate neutrophils in the damaged tissues ${ }^{3}$ and is a key player in the pro-inflammatory cytokine cascade. In this study, the mean increase in IL-8 exceeded $500 \%$ and was accompanied by substantial increases in IL-6, as well as the hepatically derived acute phase proteins, CRP and amyloid A. Despite the relatively small sample sizes of the 3 groups and the conservative non-parametric statistics used, serum CRP, an important marker of acute phase response, ${ }^{7}$ was significantly elevated in the 24-hour post-race sample of the VC500 group when compared with the placebo group. This was supported by the trends towards higher serum amyloid $A$ $(p=0.12)$, IL-6 $(p=0.11)$ and IL-8 $(p=0.14)$ post-race concentrations in the VC500 group.

Collectively, these data are also supported by recent findings. The significant increment in the 24-hour post-race acute phase protein concentration in the VC500 group confirms our previous finding of an increased acute phase response (CRP) and reduced anti-inflammatory response (lower serum cortisol concentrations) reported in the group receiving $1000 \mathrm{mg} \mathrm{VC}$ in our previous paper. ${ }^{15}$ The findings of Childs et al. ${ }^{5}$ who showed that supplementation with the equivalent of 750 - $1000 \mathrm{mg} \mathrm{VC}$ daily for 7 days prior to a brief, intense session of eccentric resistance exercise, resulted in significant increases in indices of oxidative stress which included serum-free iron, lipid hydroperoxides and 8-iso prostaglandin $F_{2}$ alpha, also lend support to this finding. This contention is further supported by the significantly lower cortisol and anti-inflammatory cytokine (II-10 and IL-1ra) response (reported in Peters et al. ${ }^{14}$ ).

Notwithstanding the relatively small sample sizes and the fact that field work of this nature does not allow strict control of dietary intakes during the race, the trends of a pro-inflammatory response in the VC500 group are too striking to ignore and may well support in vitro findings of an ascorbic acid-induced pro-inflammatory response. These include inhibition of the hydrogen peroxide $\left(\mathrm{H}_{2} \mathrm{O}_{2}\right)$, neutralising activity of catalase by complexing with the haeme group of this anti-oxidative enzyme, ${ }^{12,13}$ the inability of the vitamin to scavenge $\mathrm{H}_{2} \mathrm{O}_{2}{ }^{1}$ and its paradoxical action in preventing the auto-oxidative inactivation of NADPH-oxidase by acting as a scavenger of hypochlorus acid $(\mathrm{HOCl})$, which results in increased production of $\mathrm{H}_{2} \mathrm{O}_{2}$ by activated phagocytes. ${ }^{1}$
Although a pro-inflammatory response could reasonably be expected to augment innate host defences against microbial and viral pathogens, possibly contributing to the lower incidence of post-race upper respiratory tract infection in vitamin C-supplemented ultramarathon athletes, ${ }^{16}$ this may, however, be offset by an increase in the potential threat of inflammationmediated tissue damage.

\section{Acknowledgements}

We thank Mrs Tonya Esterhuizen for assistance with the statistical computation of data reported in this paper.

\section{REFERENCES}

1. Anderson R, Lukey PT. A biological role for ascorbate in the selective neutralization of extracellular, phagocyte derived reactive oxidants. Ann N Y Acad Sci 1987; 498: 219-47.

2. Ashton T, Young IS, Davison GW, et al. Exercise induced endotoxaemia: the effect of ascorbic acid supplementation. Free Radic Biol Med 2003; 35: 284-91.

3. Baggiolini M. Novel aspects of inflammation: Interleukin-8 and related chemotactic cytokines. Clinical Investigator 1993; 71: 812-14.

4. Bieri JG, Tolliver TJ, Catignani GL. Simultaneous determination of retinol and (tocopherol in serum and plasma by liquid chromatography. Clin Chem 1983; 29: 708-12.

5. Childs A, Jacobs C, Kaminski T, Halliwell B, Leeuwwenburgh C. Supplementation with vitamin $\mathrm{C}$ and $\mathrm{N}$-acetyl-cysteine increases oxidative stress in humans after an acute muscle injury induced by eccentric exercise. Free Radic Biol Med 2001; 31: 745-53.

6. Dill DB, Costill DL. Calculation of percentage changes of blood, plasma and red cells in dehydration. J Appl Physiol 1974; 37: 247-8.

7. Fallon KE The acute phase response and exercise: the ultramarathon as prototype exercise. Clin J Sport Med 2001; 11(1): 38-43.

8. Lambert MI, Dennis SC. Delayed onset muscle soreness. South African Journal of Sports Medicine 1994; 1: 18-20.

9. Malo C, Wilson JX. Glucose modulates vitamin C transport in small intestine brush border vesicles. J Nutr 2000; 130: 63-9.

10. Nieman DC, Henson DA, Butterworth DE, et al. Vitamin C supplementation does not alter the immune response to 2.5 hours of running. Int $J$ Sport Nutr 1997; 7: 173-84.

11. Nieman DC, Peters, EM, Henson DA, Nevines El, Thompson MM Influence of vitamin $\mathrm{C}$ supplementation on cytokine changes following an ultramarathon. J Interferon Cytokine Res 2000; 20: 1029-35.

12. Orr CWM. Studies on ascorbic acid. I. Factors influencing the ascorbatemediated inhibition of catalase. Biochemistry 1967; 6: 2295-3000.

13. Pederson EW, Ostowski K, Ibfedt T, et al. Effect of vitamin supplementation on cytokine response and on muscle damage after strenuous exercise. Am J Physiol Cell Physiol 2001; 289: C1570-5.

14. Peters EM, Anderson R, Nieman DC, Fickl H, Jogessar V. Vitamin C supplementation attenuates the increase in circulating cortisol, adrenaline and anti-inflammatory polypeptides following ultramarathon running. Int $J$ Sports Med 2001b ; 22: 537-43.

15. Peters EM, Anderson R, Theron AJ. Attenuation of the increase in circulating cortisol and enhancement of the acute phase response in vitamin Csupplemented ultramarathoners. Int J Sports Med 2001a ; 21: 1-7.

16. Peters EM, Goetzsche JM, Joseph LE, Noakes TD. Vitamin C as effective as combinations of anti-oxidant nutrients in reducing the incidence of upper respiratory tract infections in ultradistance runners. South African Journal of Sports Medicine 1996; 4: 23-7.

17. Poulsen HE, Weiman A, Salonen KN, et al. Does Vitamin C have a prooxidant effect? Nature 1998; 395: 231.

18. Schane JA, Johnson SR, Vandenakker CB. Delayed onset muscle soreness and plasma CK and LDH activities after downhill running. Med Sci Sports Exerc 1983; 15: 51-6.

19. Schmidt KA, Steinhilber D, Moser U, Roth HJ. L-ascorbic acid modulates 5 -lipogenase activity in human polymorhonuclear leukocytes. Int Arch Allergy Immunol 1988; 85: 441-5.

20. Sorichter S, Puschendorf B, Mair J. Skeletal muscle injury induced by eccentric muscle action. Muscle proteins as markers of muscle fibre injury. Exerc Immunol Rev 1999: 5: 5-21 